\title{
Climatology of Heavy Orographic Rainfall Induced by Tropical Cyclones over Madagascar: From Synoptic to Mesoscale Perspectives
}

\author{
Tatiana A. Arivelo ${ }^{1} \&$ Yuh-Lang Lin ${ }^{1,2}$ \\ ${ }^{1}$ Department of Energy \& Environmental Systems, North Carolina A\&T State University, USA \\ ${ }^{2}$ Department of Physics, North Carolina A\&T State University, USA \\ Correspondence: Yuh-Lang Lin, 302H, Gibbs Hall, Department of EES, North Carolina A\&T State University, \\ 1601 E. Market Street, Greensboro, NC, 27411, USA. Tel: 1-919-285-2127. E-mail: ylin@ncat.edu
}

Received: April 27, 2016

Accepted: June 13, 2016

Online Published: July 3, 2016

doi:10.5539/esr.v5n2p132

URL: http://dx.doi.org/10.5539/esr.v5n2p132

\begin{abstract}
Variability of and generation mechanisms for Madagascar rainfall are studied by conducting climatological, synoptic and mesoscale analyses. It is found the rainfall variability is highly sensitive to seasons with high variability in summer (Nov-Apr). The rainfall in summer is controlled by the Intertropical Convergence Zone (ITCZ) and orographic rainfall associated with tropical cyclones (TCs), while the rainfall in winter (May-Oct) is controlled by trade winds and local orographic rainfall along the eastern coast. Synoptic analysis reveals that major climate variations in summer are associated with ITCZ position, which is closely related to TC genesis locations and quasi-biennial oscillation (QBO). Linkages between El-Niño Southern Oscillation Index (ENSO) and Southern Oscillation Index (SOI) are identified as the cause of inconsistent dry or wet summers. Mesoscale analysis depicts the importance of the orographic effects on prevailing wind, which are controlled by the orography in both seasons. In winter, the prevailing trade winds over the Southwest Indian Ocean are from the east and are split to the north and south when it impinges on Malagasy Mountains. On the other hand, in summer the prevailing easterlies are weaker leading to the production of lee vortices, in addition to the flow splitting upstream of the mountain. Thus, the flow is classified into two regimes: (a) flow-over regime with no lee vortices under high Froude number $(\mathrm{Fr}=1.2-1.8)$ flow, and (b) flow-around regime with lee vortices under low $\mathrm{Fr}$ $(=0.88-1.16)$ flow. A case study of TC Domoina (1984) indicates that the long-lasting heavy rainfall was induced by the strong orographic blocking of Madagascar. The shorter-term (e.g., 2 days) heavy orographic precipitation is characterized by large $V_{H} \cdot \nabla h$ which is composed by two common ingredients, namely a strong low-level wind normal to the mountain $\left(V_{H}\right)$ and a steep mountain slope $(\nabla h)$.
\end{abstract}

Keywords: orographic rainfall, common ingredient, tropical cyclone, Madagascar, ITCZ, ENSO, SOI, Domoina

\section{Introduction}

Rainfall features in the tropical region are mainly modulated by the intertropical convergence zone (ITCZ) which possesses a large-scale fluctuation characterized by the complex northeast and southeast trade wind systems accompanied with bands of convective clouds and rain (see e.g., Hastenrath \& Lamb, 1978; Grodsky \& Carton, 2003). More importantly, the variation of rainfall amount over Madagascar is affected by tropical cyclone (TC) formation which is linked to the position and strength of the ITCZ (see, e.g., Duchiron, 2002). The rainfall maxima occur during the peak summer season (January-February) when the ITCZ is located at its southernmost about $10^{\circ} \mathrm{S}$ latitude enhancing the probability for a tropical cyclone to develop with respect to the favorable conditions described in different literatures (e.g., Lin, 2007).

The average number of cyclones formed per year during the cyclone season (November-April) over the South West Indian Ocean (SWIO) basin is 12.5 (Mavume et al., 2009) and the average number of tropical cyclones making landfall over Madagascar is 3.1 per year (Fitchett \& Grab, 2014). Cyclones sometimes have a destructive effect depending on its duration. From large-scale perspective, many environmental factors modulating the TC's activity in the SWIO, such as the El Niño Southern Oscillation (ENSO) and the Madden-Julian Oscillation (MJO), taking part in TC genesis (Bessafi \& Wheeler, 2005) which are both characterized by different overlapping phases with the TC's passage affecting the inter annual and intra seasonal rainfall variation (Ho et al., 2006; Ramsay et al., 2012). The effect of ENSO on Madagascar climate is poorly understood (Ingram \& Dawson, 2005) but they are closely related, according to Rocha \& Simmonds (1997). Particular study on the El Niño 
episodes shows inconsistent relationship to Madagascar rainfall (Ingram \& Dawson, 2005; Dunham et al., 2010), causing drought in some areas but wetter conditions into certain regions. Besides, assumptions such as above normal sea surface temperature (SST) and Quasi Biennial Oscillation (QBO) cyclical forcing can also add to heavy TC rainfall enhancement (Jury et al., 1993; Fitchett \& Grab, 2014).

Another environmental factor, such as the orography, may play an important role in modulating the climate of a region. In this regard, various studies demonstrated that typical tropical storm impinging onto the escarpment is able to produce devastating heavy rainfall due to complicated interaction between the orographic blocking and uplifting of the incoming moist airstream which could be conditionally or potentially unstable such as that over the Appalachians (DiMego \& Bosart, 1982; Lin, 2007). Furthermore, studies focusing on the mechanisms inducing and/or enhancing orographic rain (e.g., Smith, 1979; Houze, 1999; Lin, 1993; Chu \& Lin, 2000) were undertaken, in which the majority of heavy orographic rainfall events over mesoscale mountains are caused by either 1) the upslope rain in conjunction with conditional or potential instability, or 2) the leeside convective rain either advected in from the windward slope region (Lin et al., 2001). Hence, the dynamics of the orography effect on the cyclone tracks were described through the nondimensional parameter, such as the Froude number which is defined as $\mathrm{Fr}=U / N h$ where $U$ is the basic flow speed, $N$ the Brunt-Vaisala frequency, and $h$ the mountain height (e.g., see Lin, 2007). Recently, Rostom \& Lin (2016) have made an attempt to estimate the heavy orographic rainfall in the Appalachian mountain associated with the Hurricanes Hugo (1989) and Isabel (2003) in which the dynamics behind the heavy rainfall was highlighted.

Characterized by massifs above $2600 \mathrm{~m}$ high and a central mountain range of $1200 \mathrm{~km}$ long, little has been investigated on heavy orographic rainfall induced by the TCs over Madagascar from mesoscale perspective. Therefore, the main objective of this paper is to study the variability of and generation mechanisms for Madagascar orographic rainfall by conducting climatological, synoptic and mesoscale analyses. First, the climatology of Madagascar rainfall is investigated by several statistical analyses of the rainfall records from 18 observing stations. Then, synoptic analysis of the meteorological pattern in summer and winter is conducted using climate variables (e.g. surface wind direction and speed) in which more explanation is provided concerning ITCZ and orographic effect in modulating Madagascar climate during both seasons. Besides, this study will also evaluate the linkage between precipitation and large-scale phenomena and their sensitivity to the rainfall variability all along the cyclonic season. Lastly, specific case featuring the topographic contribution to the rainfall variability from mesoscale point of view is tackled through the severe tropical storm Domoina (1984) (Wikipedia, 2016) striking the country from the east coast on January 21 producing heavy precipitation, causing 42 deaths and \$25 million in damage (Jury et al., 1993). The paper is organized as follows. Sections 2 and 3 describe the data and method, and the experimental design and Madagascar rainfall climatology, respectively. Synoptic and mesoscale analyses are presented in Sections 4 and 5, respectively. Concluding remarks can be found in Section 6.

\section{Data and Method}

In order to initiate the rainfall study, monthly rainfall recorded from 56 observation stations were obtained from the National Meteorological and Hydrological Services in Antananarivo. The readers are reminded that the data acquired are not perfect in quality and quantity because of the inconsistencies in length and missing values within the time series. Essentially, the reliability of the output results remains compromised unless selection procedure is not applied to the raw data. Ultimately, time series from 18 stations for the period 1951-2003 with minimum gaps are retained and utilized to analyze Malagasy rainfall from probabilistic approach underlying the gamma distribution defined by the probability density function (pdf) law

$$
f(x)=\frac{x^{\alpha-1}}{\beta^{\alpha} \Gamma(\alpha)} e^{-x / \beta}
$$

with $x,>0$, where $x$ is the variable to be evaluated, the distribution shape parameter,the scale parameter and is the gamma function (Wilks, 1995). This approach is aiming at estimating the probability of expecting any amount of monthly cumulative rainfall within summer and winter seasons over 53 years. Besides, the inverse-distance weighting interpolation is applied to the data in order to fill the gaps in the time series in which the weighting function is given by

$$
w_{i}=\frac{1}{d_{i}^{2}}
$$

where $d_{i}$ is the distance between two $i$ points within a sampling circle that includes at least five sample points. 
This approach will serve for mapping the climatology of rainfall over 53 years. Circulation structure and variability of climate in both winter and summer seasons were also examined using moisture flux, large-scale precipitation and wind profiles of $2.5^{\circ}$ resolution at $1000 \mathrm{mb}$ over the period 1952-2002 from the Meteo of La Reunion, based on the European Centre for Medium-Range Weather Forecast (ECMWF) adapting the model physics to the SWIO.

Monthly rainfall datasets during the period 1951-2000 of $0.5^{\circ}$ resolutions from the Global Precipitation Climatology Center (GPCC) are used to feature the most important modes of rainfall variability and detect mechanisms for producing inter annual variability particularly in summer. Principal component analysis (PCA) (Pearson, 1902; Hotelling, 1935) or empirical orthogonal functions (EOF) technique (Lorenz, 1956) is applied to compress the GPCC rainfall data to describe the variability in the time series. Starting from three-dimensional data set varying over longitude, latitude and time, this technique reconstructs the initial data into a set of two-dimensional loadings (eigenvectors or EOFs) that are spatially dependent and one-dimensional principal components that are time dependent. Each EOF often comes with an explained variance that captures the variability in the original data set in one pattern. Further explanation on this method could be found in different statistical literatures (e.g., Wilks, 1995).

The $p$-value in statistics (Nuzzo, 2014) is acquired to test if there is a relationship between temporal coefficients of the rainfall and the indices of the oceanic/atmospheric variables. This hypothesis is accepted for a $p$-value equal or smaller than $5 \%$ or $1 \%$. Among the climate indices are TC index, southern oscillation index (SOI), quasi-biennial oscillation (QBO), and El Niño-Southern Oscillation Index (ENSO). Essentially, TC data are collected and archived by the Reunion Regional Specialized Meteorological Center (RSMC) restricted in the western and central portion of the South Indian Ocean. The TC index datasets are based on the frequency of the TC genesis in that region. Besides, the SOI, QBO, ENSO datasets are obtained from the National Centers for Environmental Prediction (NCEP) and the details of NCEP reanalysis data could be found in Kalnay et al. (1996) and Kistler et al. (2001).

In addition, the NCEP/NCAR Reanalysis surface datasets of meteorological variables, such as $4 \mathrm{x}$ dailysurface wind $(u)$, relative humidity $(q)$ data at sigma level $995 \mathrm{mb}$ at $2.5^{\circ}$ resolution, that can be retrieved from the ESRL (2016), are widely utilized by other authors to study the heavy orographic rainfall induced by the TC Domoina on January 22,1984 . In this study, the daily wind data at $850 \mathrm{mb}$ over the period 1979-2002 are used and combined with the orographic data to initiate the mesocale study. The nonlinearity of the flow is measured by the Froude number (Fr) as defined earlier. The higher the Froude number, the weaker the orographic blocking (e.g., Lin, 2007). Physically, this definition of the Froude number can be viewed as the ratio of kinetic energy to potential energy of the stratified flow.

The orographic rainfall index (ORI) proposed by Rostom and Lin (2016) is estimated with the vertical moisture flux for a strong upward vertical motion $w$ induced by low-level winds within the circulation of the storm hitting the high terrain. The ORI is approximately proportional to $(u \partial h / \partial x+v \partial h / \partial y)$, where $u$ and $v$ are horizontal wind components in $x$ and $y$ directions, respectively, and $\partial h / \partial x$ and $\partial h / \partial y$ are the slope steepness of the mountain in $x$ and $y$ directions, respectively, in response to lower boundary forcing. For a basic-state airflow moving perpendicularly to a north-south oriented long mountain, $v$ must vanish. Hence, finally we obtain $w \approx u \partial h / \partial x$.

Due to lack of observation data, daily rainfall data derived from the ECMWF model with $55 \mathrm{~km}$ grid spacing dated on 22 January 1984 is used for comparison with the calculated 24h-cumulated of the vertical moisture flux $w q$.

\section{Experimental Design and Madagascar Rainfall Climatology}

\subsection{Rainfall Records}

The means and standard deviations of the monthly rainfall records plus metadata from the meteorological service are considered to cluster the data into seven regions (Fig. 1). In addition, in order to define the probability distribution of rainfall, gamma distribution is applied to the monthly regional data during the period of 1951-2003. The results are generally showing high variability on the rainfall distribution in different regions. Hence, Figure 2 shows that the probability of getting 50-200 $\mathrm{mm}$ is generally high during the summer season over 53 years in every region except for the southwest region that receives frequent but meeker amount of rainfall. The lack of rainfall in the southwestern region is caused by a typical semi-arid climate. Furthermore, within the period of November to April (summer), the central-east region has a low probability to receive monthly precipitation of $1000 \mathrm{~mm}$ which is comparable to the maximum precipitation, $1100 \mathrm{~mm}$ over 50 years, recorded in the northwest region of Madagascar (Fig. 2). 


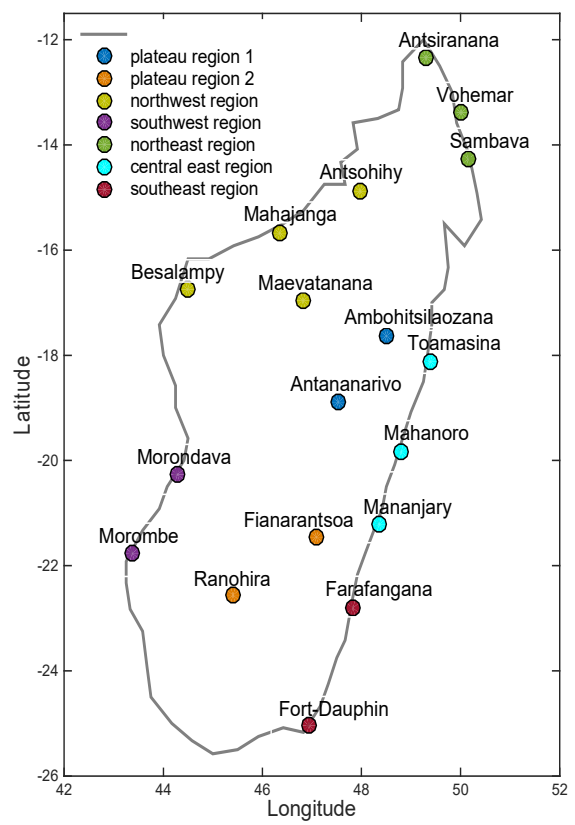

Figure 1. Classification of Madagascar into seven regions according to its rainfall records

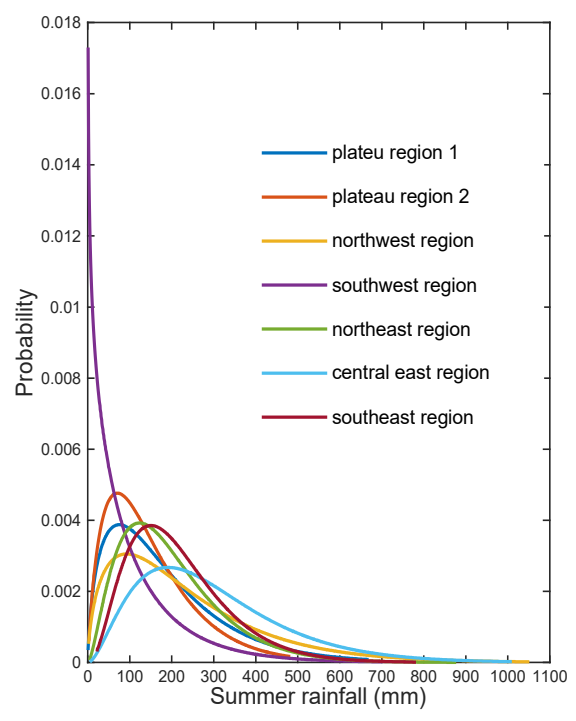

Figure 2. Probability distribution of rainfall for the period of Nov-Apr (summer) over 50 years in different regions of Madagascar

Similarly, in the west and highland regions, April (Fig. 4) is characterized by a subtle rain retreat that continues to experience total dryness within the winter (May-Oct) but the eastern coast, including northeast, central-east and southeast regions, remains rainy and often flooded (Fig. 3) with increased probability of getting precipitation ranging from 100 to $150 \mathrm{~mm}$. However, the probability distribution of rainfall has clearly distinguished the west from the east regions in winter.

The 53-year average monthly precipitation (Fig. 4) for Madagascar is also described in this study in which the precipitation reaches up to $450 \mathrm{~mm}$ in Jan-Mar. East coast is the rainiest region of the island, unlike the southern region which is characterized by a semi-arid climate and sometimes experiences chronic dryness. In summer, the mean precipitation decreases slightly toward the south, especially the southeast region experiences less than 50 $\mathrm{mm}$ yearly accumulated rainfall. Although there are variabilities shown in the rainfall records, the factors causing these variabilities will be discussed from different aspects. 


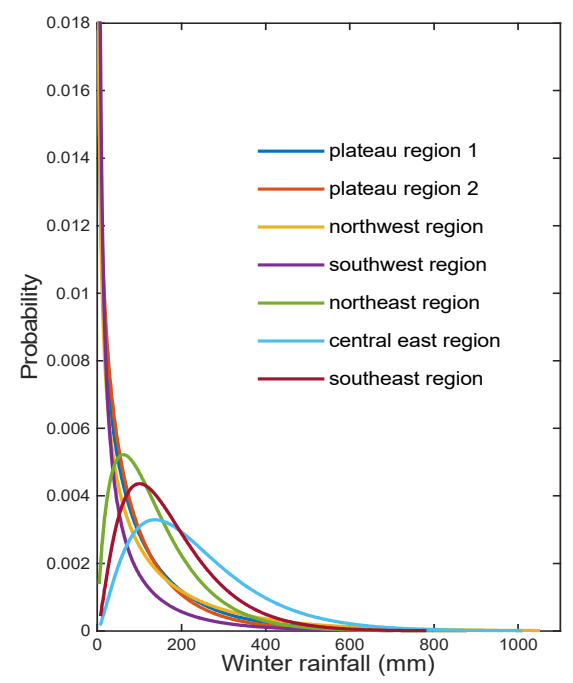

Figure 3. Probability distribution of rainfall for the period of May to Oct (winter) over 50 years in different regions of Madagascar

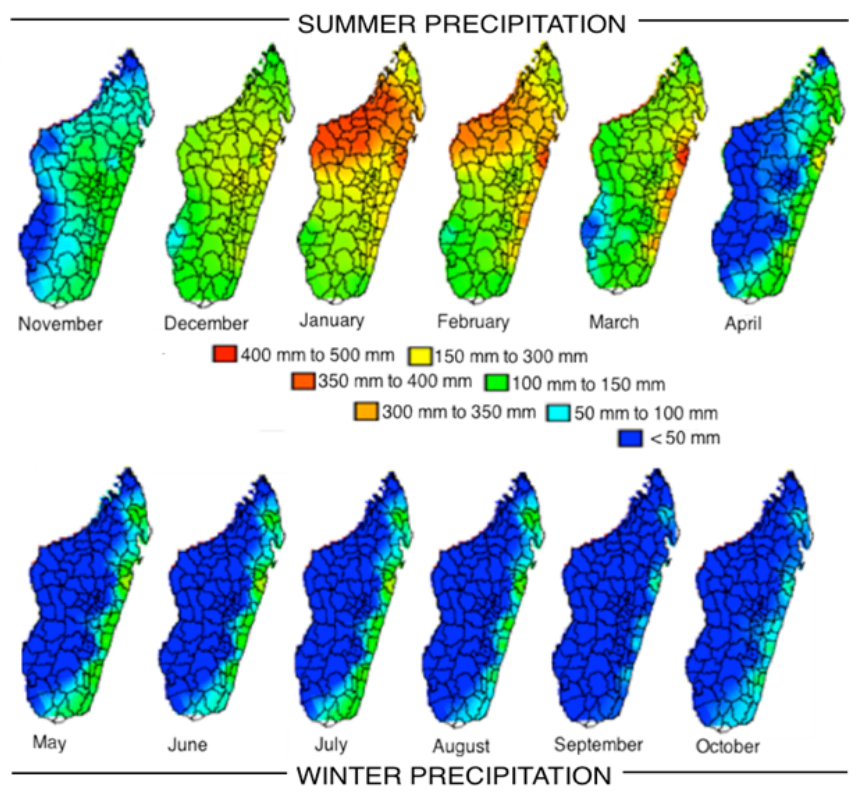

Figure 4. Madagascar rainfall climatology for the period of 1951-2003

\subsection{Orographic Influences on Madagascar Precipitation}

Located in the tropical region of SWIO, Madagascar is an island extending some $1650 \mathrm{~km}$ from $12^{\circ}$ to $25^{\circ} \mathrm{S}$ latitude, united with the African continent through the Channel of Mozambique from the longitude $41^{\circ} \mathrm{E}$. Adding to its geography and oceans, Madagascar relief plays an important role in its varied climatic conditions (e.g., see Donque, 1975). Characterized by a mountain range of $1600 \mathrm{~m}$ high in the plateau that runs from north to south through its length, Madagascar also has massifs above $2600 \mathrm{~m}$ with an asymmetric cross profile in both sides (Fig. 5) and an abrupt rise in height from the East attaining the highland region with a sharp cliff. 


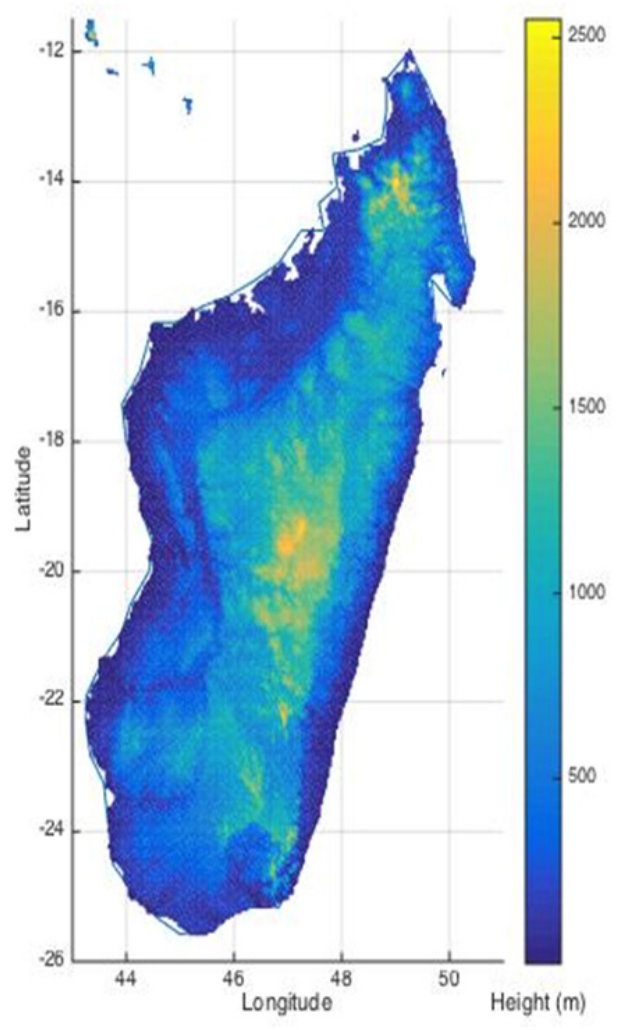

Figure 5. Madagascar topography

The airstream from the southern Indian Ocean is able to release latent heat while being lifted by the Madagascar Mountains reaching the lifting condensation level. This is evidenced by the strong upward motion at $700 \mathrm{mb}$ associated with the lifting over the central mountain range of Madagascar in both seasons over the island (Fig. 6). The observed rainfall amount is larger in summer (Nov-Apr) when the wind speed is weaker (Fig. 7), which is associated with the ITCZ. However, in winter the upward motion is less critical than in summer because it mainly results from local sensible heating over the mountain along the eastern coast. Although Figure 6 shows the correlation between the rainfall distributions over Madagascar is related to the mountains, it requires more in-depth analysis, especially at mesoscale, to provide more concrete evidence.

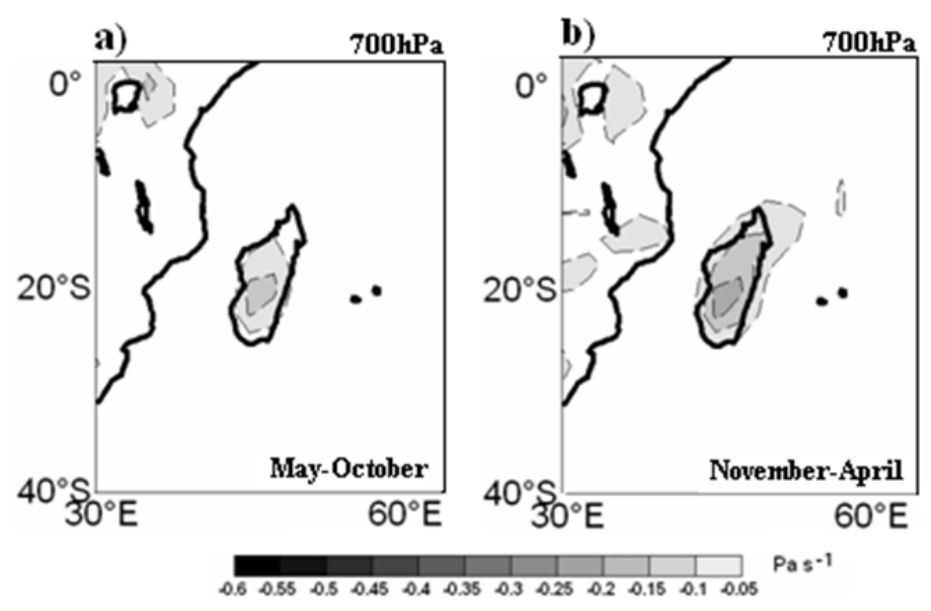

Figure 6. Vertical wind velocity fields during (a) winter and (b) summer in thesouthwestern Indian Ocean for the period of 1952-2002 


\section{Synoptic-Scale Analysis}

\subsection{Interseasonal Variation}

The climate over the SWIO in summer is dominated by the position of ITCZ, which contributes to the rainy season in Madagascar. Figure 7 shows a synoptic-scale analysis of the 50-year average wind field in summer revealing a deep convection around $10^{\circ} \mathrm{S}$ where the mean axis of the maximum rainfall is located. The moist and convective region associating the cross-equatorial monsoon flux in the northwest with the southeast trade winds can easily drive large-scale precipitation directed to the island. Furthermore, meridional excursion of the ITCZ from November to April establishes a favorable condition for tropical cyclogenesis in the Indian Ocean (Fig. 8) bringing heavy rainfall to the island.
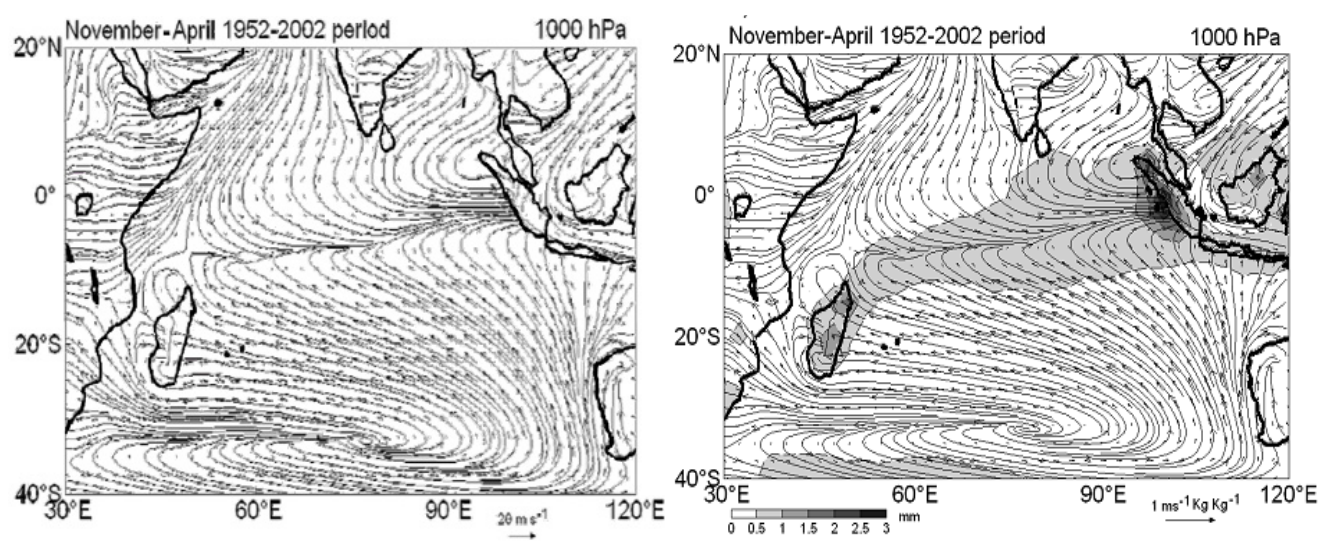

Figure 7. The 50-year mean wind field (left) and moisture flux with large-scale precipitation (right) near surface over the SWIO during the summer

At synoptic scale, the wind patterns over the SWIO are split by Madagascar, which results in a complex situation in the Channel of Mozambique in addition to the cross equatorial flow from the northern hemispheric monsoon (Fig. 7). Briefly speaking, the summer season in the SWIO consists of the ITCZ in its southernmost geographical position about $10^{\circ} \mathrm{S}$ latitude close to Madagascar and the Mascareign's anticyclone located far to the East about $80^{\circ} \mathrm{E}$ longitude in summer. In other words, ITCZ location is mainly the determining factor yielding maximum rainfall over the island in summer.

The winter season is characterized by high-pressure weather systems that occur in the extratropical region, which have significant effect on Madagascar climate and its meteorological patterns. At synoptic scale, according to the wind-field situation in winter for 1952-2002, prevailing trade winds from the east are deflected by Madagascar to the north and slightly to the south whereas the cross equatorial wind along the Somalia coast (Fig. 9). Equally, the anticyclonic circulation near the southeastern Madagascar $\left(55^{\circ} \mathrm{E}, 35^{\circ} \mathrm{S}\right)$ strengthens the southeasterly flow inducing local orographic rainfall along the east coast.

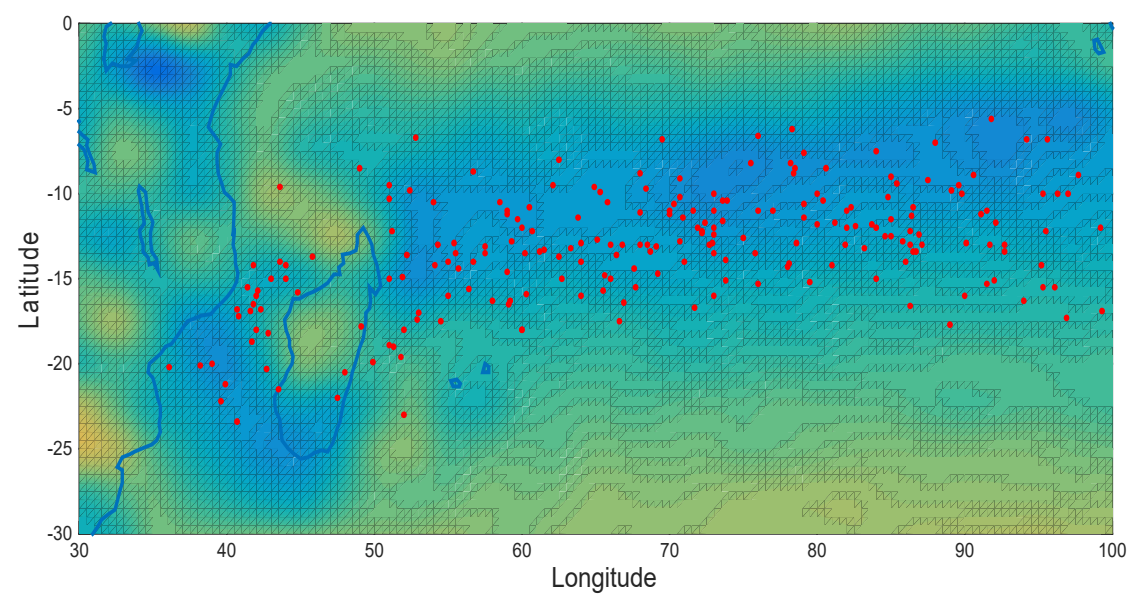

Figure 8 . The average positions of the convective systems (blue) and cyclogenesis locations (red dots) in summer for the period of 1979-2002 


\subsection{Intraseasonal Variation}

The ITCZ and southeasterly winds are the dominant meteorological features over the SWIO and play important roles in the rainfall amount and distribution for Madagascar. The rainfall amount mainly varies throughout the year (Fig. 4) due to different large-scale wind patterns in the SWIO region (Figs. 7 and 9). In addition to the interseasonal variation, the monthly average wind speed over the SWIO is shown in Fig. 10, which reaches its peak in July-August $\left(\sim 9 \mathrm{~ms}^{-1}\right)$ and its minimum in January-February $\left(\sim 4.5 \mathrm{~ms}^{-1}\right)$. The major intraseasonal variation is also demonstrated by the time-altitude climatological monthly mean relative humidity and pseudoequivalent potential temperature over the Reunion Island (Fig. 11). In the lower layer $(0-3 \mathrm{~km})$, the atmosphere is wet especially in January-March and June-September. In this lower layer near surface, the atmosphere is potentially unstable (Fig. 11b), which may be triggered to release the instability during these two time periods, especially in summer, if there is enough forcing, such as orographic lifting. Note that the high humidity is focused in the lower layer $(0-3 \mathrm{~km})$ and capped above by the trade wind inversion, thus it inhibits deep convection. Relatively speaking, the potential instability in the lower troposphere in winter, especially in the period of June-September, is not as strong as that in summer (Fig. 11b).
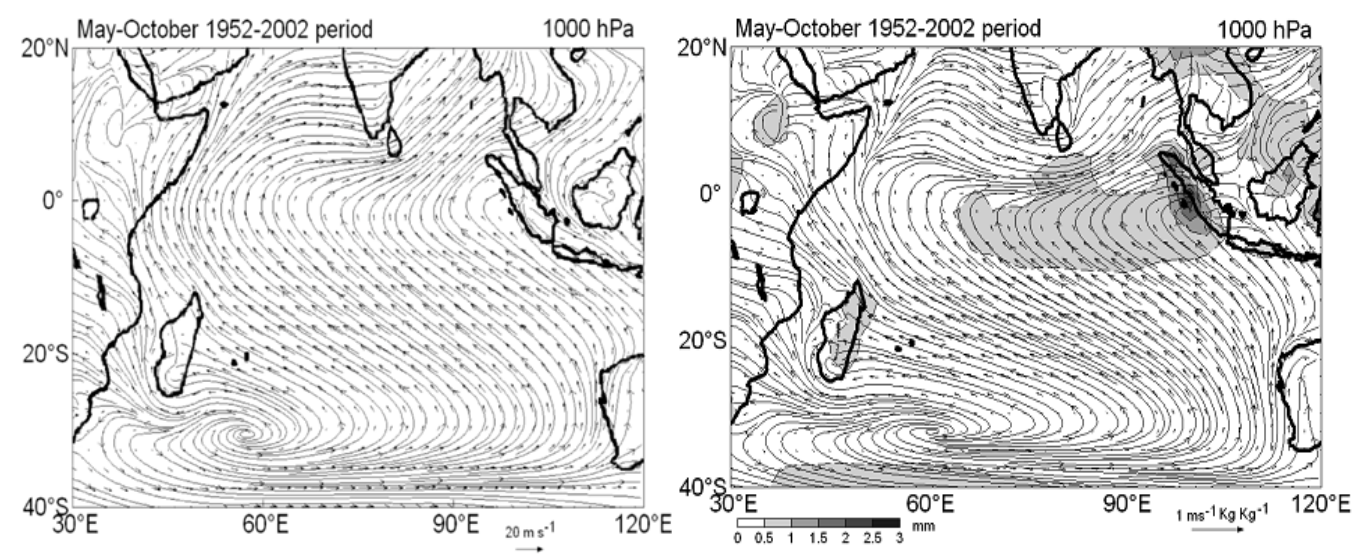

Figure 9. The 50-year mean wind field (left) and specific humidity with large-scaleprecipitation (right) near surface over the SWIO during the winter

\subsection{Variation in Rainfall Modes}

Many studies concerning the South Indian Ocean climate variability have been undertaken let alone its structure and mechanisms. However, the current study attempts to quantify the contribution of different mechanisms to Malagasy rainfall during the summer. As a result, during the summer season $49 \%$ of variations in the rainfall time series $\mathrm{PC}_{1}$ have a valid relationship with the tropical cyclone and $\mathrm{QBO}$ with $5 \%$ probability of rejecting this hypothesis. The spatial pattern of the variations $\mathrm{EOF}_{1}$ is showing a convective nature of rainfall emphasizing the importance of the large-scale pattern anomalies (Fig. 12a) associated with the southernmost position of the ITCZ in summer where the TCs genesis normally takes place (e.g., Ho et al., 2006). Furthermore, the east phase of QBO characterized by a stronger intensity and longer duration and associated with the warming of the Indian Ocean waters can strengthen the intensity of the TCs during the summer season (Jury et al., 1995).

The second mode of rainfall $\mathrm{PC}_{2}$ explain $24 \%$ of the summer time data variance and has only $1 \%$ and $5 \%$ chances of not having relationship with the ENSO and SOI respectively. The spatial pattern of $\mathrm{EOF}_{2}$ shows North-South polarity with more highlights on the north region where January and February rainfall climatology seem to have similar feature (Fig. 12b). However, the relationship summer rainfall and ENSO is not strong enough due to the North-South contrast causing inconsistency in the climate response to Madagascar (Rocha \& Simmonds, 1997). The third mode $\mathrm{PC}_{3}$ of rainfall explained by $10 \%$ of the rainfall variations shows the importance of the height elevation associated with East-West polarity despite its non-linkage with any climate mechanism (Fig. 12c), and also the lack of orographic-induced rainfall index in a larger scale. Limitation in the synoptic scale analysis suggests mesoscale study scrutinizing the effect of Madagascar orography for producing heavy rainfall induced by tropical cyclones.

In this regard, Lin et al. (2005) proposed the importance of analyzing the Froude number and its related flow 
regimes and how efficient the blocking effect is adding to the common ingredients (Lin et al., 2001) enabling the increase of the potential energy for producing heavy orographic precipitation.
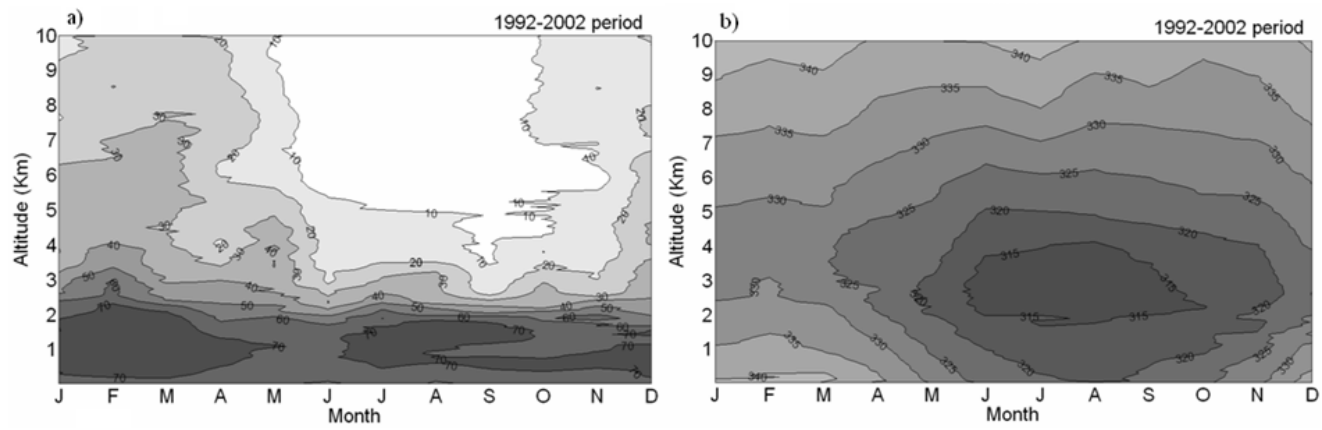

Figure 11. Time-altitude climatological monthly mean of a) relative humidity and b) pseudoequivalent potential temperature $(\mathrm{K})$ over Reunion Island [centered at $\sim\left(21^{\circ} \mathrm{S}, 55^{\circ} \mathrm{E}\right)$ ]
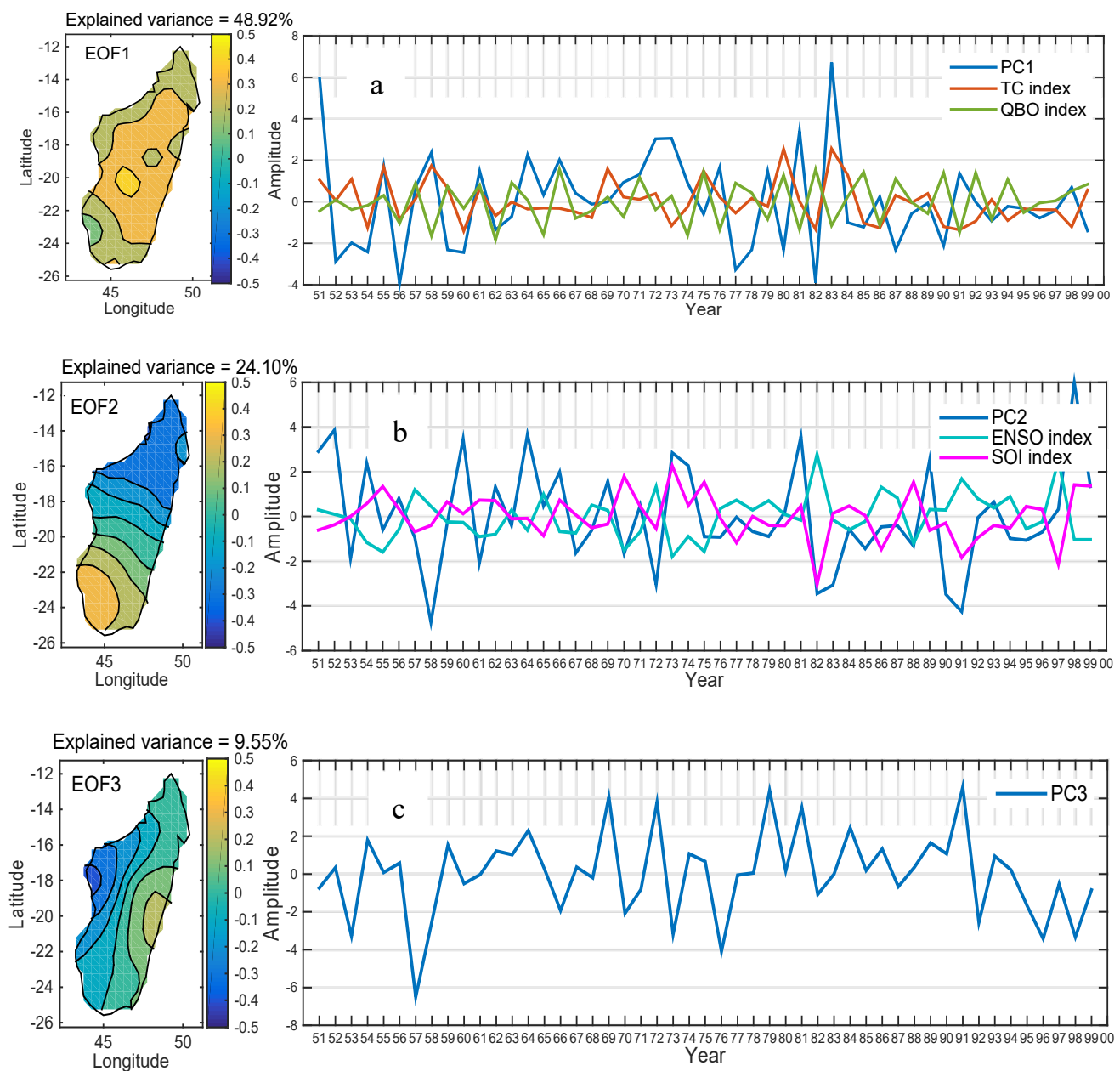

Figure 12. Spatial $\left(\mathrm{EOF}_{1-3}\right)$ and temporal $\left(\mathrm{PC}_{1-3}\right)$ representation of the main rainfall patternsand the related climate phenomenon with $95 \%$ to $99 \%$ confidence interval

\section{Mesoscale Analysis}

The isolated nature of Madagascar is an ideal environment for investigating the orographic effect on TCs. Extending $1583 \mathrm{~km}$ in length and $546 \mathrm{~km}$ in width, Madagascar central mountain range is estimated at $1300 \mathrm{~m}$ 
with massif above $2600 \mathrm{~m}$ mainly in the inland regions. The challenge in predicting heavy rainfall associated with TC affecting Madagascar is the aim of this mesoscale analysis.

\subsection{Measuring the Nonlinear Parameter}

Linear dynamics are no longer applicable when the mountain is very high and associated with a very slow moving basic flow. However, in the dynamics of nonlinear flow, phenomena such as upstream blocking, wave breaking, severe downslope winds and lee vortices are expected in the mesoscale with horizontal scales of 2 to $2000 \mathrm{~km}$. For a mountain height ( $h$ from $500 \mathrm{~m}$ to $2600 \mathrm{~m}$ ) and Brunt-Vaisala frequency $\left(N=0.01 \mathrm{~s}^{-1}\right)$, the Froude number $(\mathrm{Fr}=U / \mathrm{Nh})$ at $1000 \mathrm{mb}$ level for a 50 -year average wind field (Fig. 10) is estimated at the range of 1.2 to 1.8 in winter. Similarly, orographic blocking at $850 \mathrm{mb}$ is analyzed over the period 1979-2002. It describes stratified, uniform trade winds flow passing over the mountain (Smolarkiewicz and Rotunno 1989), as shown in Figure 13.

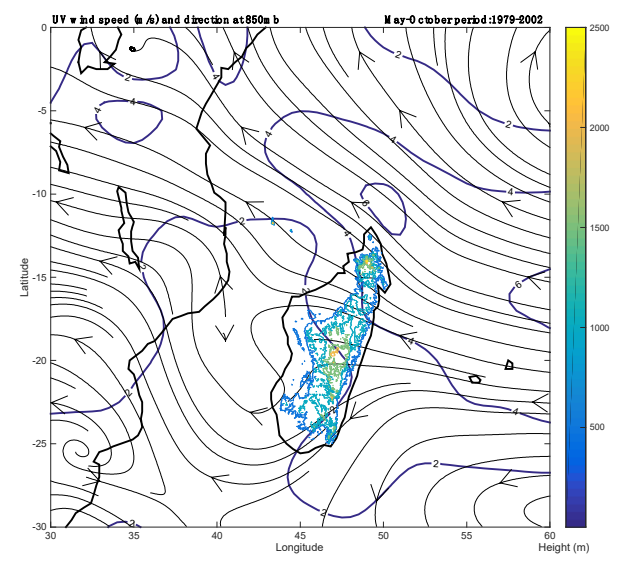

Figure 13. Average $850 \mathrm{mb}$ streamlines in winter (May-Oct) over the period of 1979-2002, superimposed with the height $(\mathrm{m})$ field

However, during the summer season discontinuous streamlines are detected at $850 \mathrm{mb}$ split by the topography of Madagascar. Obviously, the wind patterns are flowing around the mountain generating lee vortex in the channel of Mozambique where a trough is observed (Fig. 14). Furthermore, due to the oval structure of the overall mountain and its tilted position to the right, the secondary flow-over to the north is quasi re-circulated adding to the trans-equatorial flow interaction that distresses and weakens the vortex formation. Evidently, the blocking grows strong for a weak basic flow $(U)$ when the Froude number ranges from 0.2 to 0.1 for an increasing height up to $2600 \mathrm{~m}$. Furthermore, the corresponding Froude number at $1000 \mathrm{mb}$ level for 50 -year average wind field (Fig. 9) ranges from 0.88 to 1.66 in summer. It shows the dependence of the nonlinear parameter to the wind speed, i.e. the ability of the wind to lift up due to the increasing potential energy and also its sensitivity to the pressure level.

The tropical cyclone activity is very active when the basic flow is getting weak especially in January and February. The decrease of the Froude number (or inverse nonlinear parameter) to approximately 0.9 at $1000 \mathrm{mb}$ and 0.1 at $850 \mathrm{mb}$ during this particular period is accompanied with a strong blocking characterized by an initial vortex formation in the Indian Ocean (Fig. 15). The vortex is then fragmented by the orography and regenerated on the lee side region. In addition, this phenomenon can produce orographic precipitation that could go beyond normal when accompanied with the TC. Hence, the next paragraph will cover the analysis of such mechanism. 


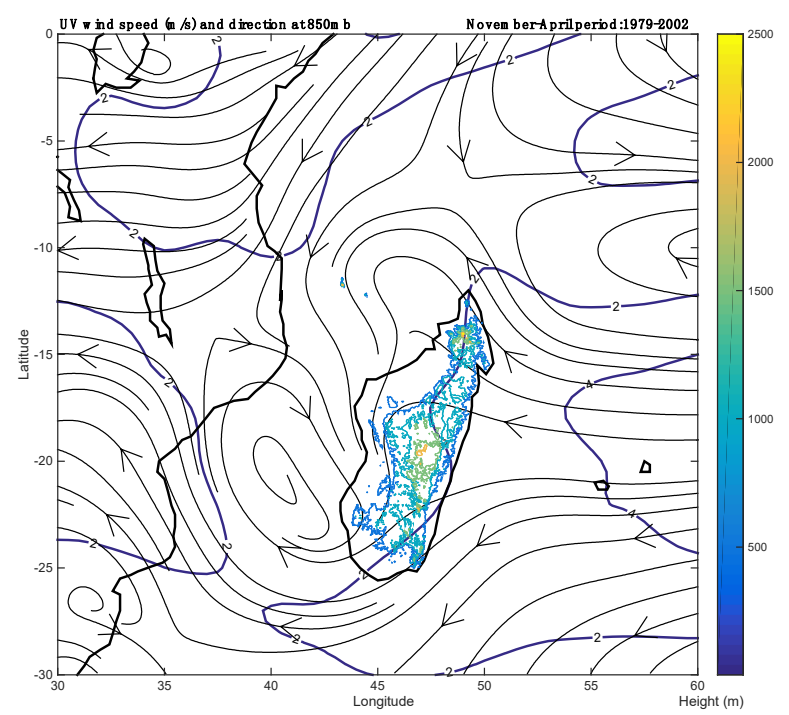

Figure 14. Average $850 \mathrm{mb}$ streamlines in summer (Nov-Apr) over the period of 1979-2002, superimposed with the height $(\mathrm{m})$ field

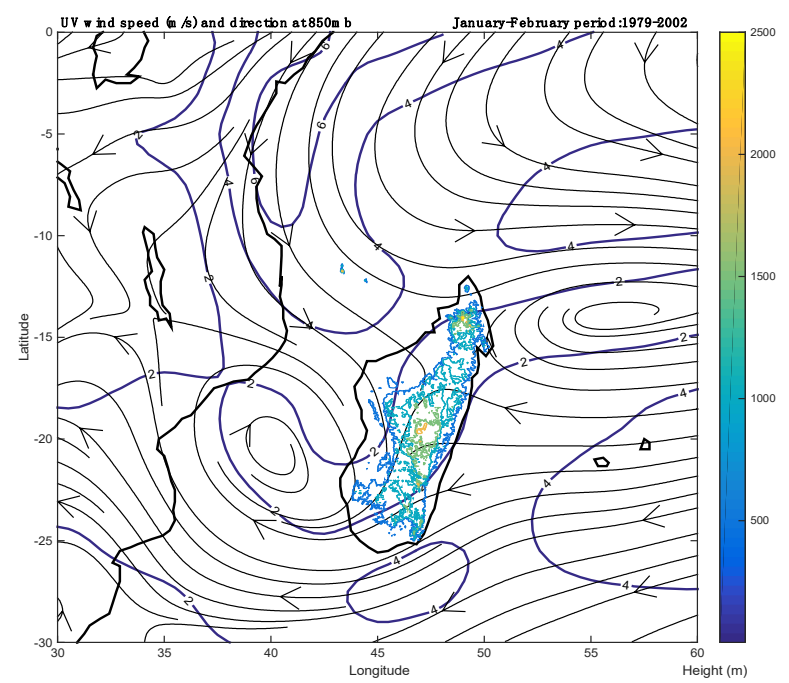

Figure 15. Average $850 \mathrm{mb}$ streamlines in Jan-Feb over the period of 1979-2002, superimposed with the height (m) field

\subsection{Case Study: Tropical Storm Domoina (1984)}

\section{(a) Synopsis}

In January and February of 1984, favorable conditions for tropical cyclogenesis in the SWIO were developed, including the above normal sea surface temperatures (SST) and an active monsoon trough (Jury et al., 1993). On January 16, a mesoscale convective vortex persisted off the northeast coast of Madagascar, associated with the ITCZ. A storm was initially tracked to the west-northwest with estimated winds about $65 \mathrm{~km} \mathrm{~h}^{-1}$ (40 mph). On January 18, the storm had begun moving to the southwest, and Méteo France (MFR) estimated that it was weakened to tropical depression status. On January 19, the Joint Typhoon Warning Center (JTWC) began the warning on the Tropical Cyclone baptized as Domoina (Knapp et al., 2010). The TC became a moderate tropical storm on the same day according to MFR. The storm made its landfall on January 21 in the area of Andevoranto located south to Tamatave i.e. in the central east region of Madagascar. While crossing Madagascar on a westward trajectory, Domoina was weakened to $55 \mathrm{~km} \mathrm{~h}^{-1}$ (35 mph) after the landfall. On January 23, the storm emerged into the Mozambique Channel near Belo. Moving southwestward, Domoina became a severe tropical 
storm on January 25, strengthened by the flow-around regime due to the blocking of Madagascar orography (Fig. 16). Early on January 28, Domoina made a second landfall on southeastern Mozambique that was slowly weakened over land while moving across southern Mozambique. On January 30 Domoina crossed into Swaziland and then into eastern South Africa, weakened into a tropical depression while passing near Durban (Knapp et al., 2010). Afterward, the system had been dissipating till February 2, when it was just offshore the east coast of South Africa according to the MFR.

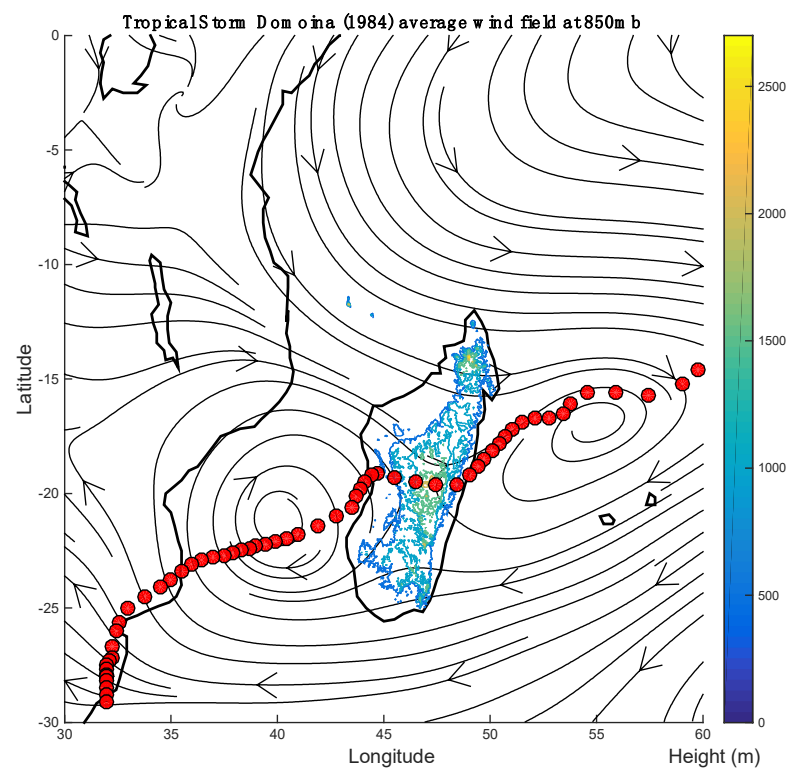

Figure 16. Trajectory of the Tropical Storm Domoina (red dots; every $6 \mathrm{~h}$ ) and its mean $850 \mathrm{mb}$ streamlines from 16 Jan to 02 Feb 1984, superimposed with the orography (m)

(b) Assessment of the general vertical moisture flux (wq)

TCs passing over Madagascar may follow different tracks and produce different rainfall patterns, depending on the driving precipitation phenomenon. In addition to the impinging location, the angle of the TC when encountering a mesoscale mountain range largely determines the deflection of the TC track (Lin and Savage III, 2011). It was observed that tropical storm Domoina (1984) had an impinging wind perpendicular to the concave massif of Andringitra (south-plateau region) on January 22. Furthermore, a large precipitation efficiency associated with a weak wind shear was observed after the landfall and a long lifetime convective system.

In the absence of surface friction, we estimate the orographic precipitation from the general vertical moisture flux $w q$, where $w$ is the strong upward vertical motion and $q$ is the water vapor mixing ratio of the incoming flow. Therefore, the vertical moisture flux at $h_{1}$ and $h_{2}$ grid points (Fig. 17) are assessed from the point $h_{o}$ displacing with a certain wind speed $u$ and relative humidity $q$ estimated every six hours on January 22 in $275 \mathrm{~km}$ space-grid (Table 1). The lack of available $6 \mathrm{~h}$ rainfall data from the ECMWF data requires daily cumulative rainfall in each selected grid points $h_{1}$ and $h_{2}$. 


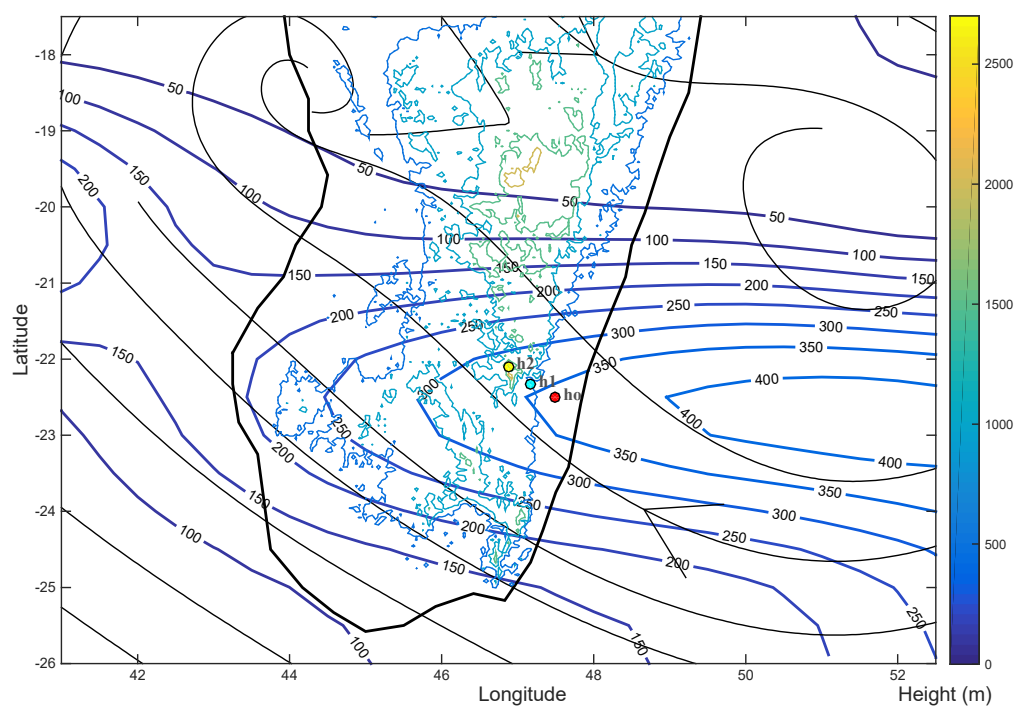

Figure 17. ECMWF total precipitation (bold blue contours; in $\mathrm{mm}$ ) and streamlines (thin black lines) on January 22, 1984 and the typical locations (dots) that feature impinging wind normal to the massif Andringitra (2658 $\mathrm{m}$ )

The estimated vertical moisture flux is compared with the observed daily precipitation on January 22, 1984 from the ECMWF. It shows that the cumulated daily precipitation observed at $h_{l}$ grid point $(343.65 \mathrm{~mm})$ is entirely produced by the moist saturated winds from the heavy rainfall associated with Domoina over the mountain of Andringitra and its strong lifting $(346 \mathrm{~mm})$. The estimated orographic rain index is in an excellent agreement with the observed precipitation at $h_{1}$ grid point.

However, the estimated vertical moisture flux at $h_{2}$ grid point $(704.97 \mathrm{~mm})$ is more than the double amount of the precipitation data $(316.56 \mathrm{~mm})$ from the ECMWF. This implies that predicting orographic rainfall is more challenging, especially when the terrain height $(h)$ rises (Tab. 1). The large discrepancy might be due to the mountain cannot be accurately resolved using coarse resolution of the ECMWF data. Besides, all conditions are fulfilled for producing heavy rainfall in which the perpendicularity of the moist wind impinging the massif at $h_{2}$ with a weaker velocity, and any other factors for the precipitation when the TC is inside the mountain that requires further study.

Table 1. Calculation of the vertical moisture flux $w q$ on January 22, 1984, compared with the approximated ECMWF daily data $(\mathrm{mm})$

\begin{tabular}{llll}
\hline Grid point $^{*}$ & $h_{0}$ & $h_{1}$ & $h_{2}$ \\
\hline Latitude & -22.5 & -22.33 & -22.1 \\
Longitude & 47.5 & 47.17 & 46.88 \\
Alt $(\mathrm{m})$ & 230 & 708 & 2194 \\
& & $\left(h_{0} \rightarrow h_{1}\right)$ & $\left(h_{0} \rightarrow h_{2}\right)$ \\
$\partial x(\mathrm{~km})$ & & $40.83 \mathrm{~km}$ & $81 \mathrm{~km}$ \\
$\partial h / \partial x$ & & 0.0117 & 0.024 \\
\hline
\end{tabular}

Wind speed perpendicular to the mountain range and relative humidity

\begin{tabular}{lllll}
\hline Time $(\mathrm{UTC})$ & $0 \mathrm{~h}$ & $6 \mathrm{~h}$ & $12 \mathrm{~h}$ & $18 \mathrm{~h}$ \\
\hline $\mathrm{u} \perp(\mathrm{m} / \mathrm{s})^{* *}$ & 7.6 & 6.6 & 7.4 & 8 \\
$\mathrm{q}(\%)$ & 98 & 100 & 99 & 100 \\
& Estimated $\mathrm{w}=\mathrm{u} \perp$ & $\partial \mathrm{h} / \partial \mathrm{x}$ at $\mathrm{h} 1$ and $\mathrm{h} 2$
\end{tabular}




\begin{tabular}{lllll}
\hline $\mathrm{w}_{1}(\mathrm{~mm})$ & 88.9 & 77.2 & 86.6 & 93.6 \\
$\mathrm{w}_{2}(\mathrm{~mm})$ & 182.4 & 158.4 & 177.6 & 192
\end{tabular}

Estimated wq at $\mathrm{h}_{1}$ and $\mathrm{h}_{2}$ 192

$\begin{array}{lllllll}\mathrm{w}_{1} \mathrm{q}(\mathrm{mm}) & 87.12 & 77.2 & 85.73 & 93.6 & 343.65 & \mathrm{~h}_{2} \\ \mathrm{w}_{2} \mathrm{q}(\mathrm{mm}) & 178.75 & 158.4 & 175.82 & 192 & 704.97 & 346.71 \\ \end{array}$

${ }^{*} h_{0}, h_{1}$ and $h_{2}$ are shown in Figure 17.

${ }^{* *} u^{\perp}=(-u \sin \alpha+v \cos \alpha)$ is the component of the incoming wind perpendicular to the mountain range.

\section{Concluding Remarks}

In this paper, we analyze the variability of Madagascar rainfall and the main factor inducing heavy rainfall from synoptic to mesoscale perspectives. For synoptic scale, climatology study is conducted to identify the large-scale phenomena which are responsible for the rainfall variability. Climatology study of monthly precipitation recorded from 1951 to 2003 features high variability during the summer (Nov-Apr) but is less volatile in winter (May-Oct).

Summer season in the SWIO is triggered by the movement of the ITCZ associated with the cross equatorial monsoon. The 53-year average monthly precipitation in Madagascar is also described in this study, which shows the precipitation up to $450 \mathrm{~mm}$ especially from January to March in the north, west and eastern regions. Eastern region is the most inundated region of the island, unlike the southern that is characterized by a semi-arid climate that normally experiences chronic dryness. Furthermore, there is a high expectation in central-east region to receive monthly precipitation $1000 \mathrm{~mm}$ within the period of November to April, which is comparable to the maximum precipitation recorded in the northwest region of Madagascar about $1100 \mathrm{~mm}$ over 53 years. Similarly, in the west and highland regions, April is characterized by a subtle rain cessation, while the regions continue to experience total dryness within the period May to October.

Besides, the winter is announced by the easterly wind produced by the extra tropical circulation located near the southeast of Madagascar. Hence, the monthly average of wind speed over the SWIO is stronger in winter attaining the maximum $10 \mathrm{~ms}^{-1}$ in July-August and becomes weaker in summer reaching $4 \mathrm{~ms}^{-1}$ in January and February that allows the wind flow to adjust itself from kinetic to potential forced system. In addition, the entire troposphere is wet from January to March in the SWIO because of the high humidity capped in the lower layer $(0-3 \mathrm{~km})$ by the trade wind inversion inhibiting deep vertical motion. Furthermore, ITCZ is a convective system enhancing favorable conditions for TC genesis over the SWIO that can be strengthened by other physical processes, such as the QBO and Southern Oscillation.

The influence of different climate phenomenon critically involves the variability of summer rainfall over Madagascar. Principal component analysis (PCA) of the precipitation data during the summer captures the prevalence of variations in time and space in three principal modes. In this regard, the main variations in the first temporal mode of rainfall during summer represented by $49 \%$ are strongly modulated by the TCs and QBO; ENSO and Southern Oscillation Index (SOI) signatures are identified to have significant relationship with the second mode of rainfall pattern representing $24 \%$ variations in the time series. However, the third mode of rainfall representing only $10 \%$ variation portrays the important contribution of the topography in inducing heavy orographic rainfall to Madagascar.

Limitation in the synoptic-scale analysis may seem to scrutinize the effect of Madagascar orography for producing heavy rainfall induced by TCs. This suggests mesoscale study. Hence, in order to understand the dynamics of orographic effect on cyclone tracks, the Froude number (Fr) for a stratified wind flow was estimated at 850 and $1000 \mathrm{mb}$. In this regard, Fr is significantly smaller at $850 \mathrm{mb}$ compared to that at $1000 \mathrm{mb}$. At 1000 $\mathrm{mb}$, it ranges from 1.2 to 1.8 in winter, and from 0.88 to 1.16 in summer. So for a system with a high speed such as the easterlies, no risk is expected in terms of rainfall quantity as it is shaping the flow-over regime. However, strong blocking effect occurs in summer when the Fr decreases, enhancing flow-around regime. It emphasizes that when a moist system such as tropical cyclone possesses a higher available potential energy; it will definitely add to the favorable condition for heavy orographic precipitation.

Therefore, a case study is undertaken in order to understand the orographic rain dynamics associated with the Tropical Storm Domoina (1984) passing over Madagascar mountains. In the absence of surface friction, the 
general vertical moisture flux $w q$ is calculated andcompared with ECMWF model derived rainfall with $55 \mathrm{~km}$ grid spacing. The estimated orographic rain index is in an excellent agreement with the ECMWF model observed precipitation at $h_{1}$ grid point. However, the estimated moisture flux at $h_{2}$ grid point is more than the double amount of the ECMWF model derived precipitation data. This implies that predicting orographic rainfall is more challenging for high terrains. The reason may be that the rise in height also increases the released latent heat, which results an overestimated convective available potential energy. Hence, it can be concluded from this study that the devastating rainfall in the mountainous region of Andringitra, i.e. in the plateau region of Madagascar, is associated with the upstream moist wind flow accompanied by the tropical cyclone Domoina (1984) impinging perpendicularly to its concave geometry. Briefly speaking, the heavy orographic rainfall induced by the TCs over Madagascar has made a notable contribution to its seasonal variability, based on mesoscale analysis.

Lastly, despite the lack of observation rainfall station, it is very important to add more case studies and include in the future research the test of the findings with the Weather Research and Forecasting (WRF) model in order to improve Madagascar climate prediction.

\section{Acknowledgments}

Discussion with Dr. A. Mekonnen is appreciated. Thorough anonymous reviews, which have improved the quality of the paper, are highly appreciated. This research was supported by the UNESCO/Keizo Obuchi - Japan Young Researchers' Fellowship Programme and the U. S. National Science Foundation Awards AGS-1265783, CNS-1126543, and CNS-1429464.

\section{References}

Bessafi, M., \& Wheeler, M. C. (2006). Modulation of South Indian Ocean Tropical Cyclones by the Madden-Julian Oscillation and Convectively-Coupled Equatorial Waves. Mon. Wea. Rev., 134, 638-656.

Chu, C.-M., \& Lin, Y.-L. (2000). Effects of Orography on the Generation and Propagation of Mesoscale Convective Systems in a Two-Dimensional Conditionally Unstable Flow. J. Atmos. Sci.,57, 3817-3837.

DiMego, G. J., \& Bosart, L. F. (1982). The Transformation of Tropical Storm Agnes into an Extratropical Cyclone. Part II: Moisture, vorticity, and kinetic energy budgets. Mon. Wea. Rev., 110, 412-433.

Donque, G. (1975). Contribution geographique a l'etude du climat de Madagascar. Nouvelle Imprimerie des Arts Graphiques, Tananarive.

Duchiron B. (2002). Variabilité interannuelle de la pluviométrie dans l'espace riverain de l'Océan Indien. Thèse de doctorat de l'université de Paris 7, 272p.

Dunham, A., Erhart, E., \& Wright, P. C. (2010). Global climate cycles and cyclones: consequences for rainfall patterns and lemur reproduction in southeastern Madagascar. Retrieved fromhttp://hdl.handle.net/1911/27596

ESRL. (2016). NCEP/NCAR Reanalysis. Earth System Research Laboratory (ESRL), NOAA. Retrieved from http://www.esrl.noaa.gov/psd/data/gridded/data.ncep.reanalysis.surface.html

Fitchett, J. M., \& Grab, S. W. (2014). A 66-year tropical cyclone record for south-east Africa: Temporal trends in a global context. Int'l J. Climatol., 34, 3604-3615.

Grodsky, S. A., \& Carton, J. A. (2003). The Intertropical Convergence Zone in the South Atlantic and the Equatorial Cold Tongue. J. Climate, 16, 723-733.

Hastenrath, S., \& Lamb, P. (1978). On the dynamics and climatology of surface flow over the equatorial oceans. Tellus, 30, 436-448.

Ho, C.H., Kim, J.H., Jeong, J.H., Kim, H.-S., \& Chen, D. (2006). Variation of tropical cyclone activity in the South Indian Ocean: El Niño-Southern Oscillation and Madden-Julian Oscillation effects.J. Geophys. Res., 111, D22101. http://dx.doi.org/10.1029/2006JD007289

Hotelling, H. (1935). The most predictable criterion. J. Edu. Psych., 26, 139-142.

Houze, R. A. (2012). Cloud Dynamics. Academic Press (2ndEd.). pp. 496.

Ingram J. C., \& Dawson, T. P. (2005). Climate change impacts and vegetation response on the island of Madagascar. Phil. Trans. Roy. Soc. Math., 363, 55-59.

Jury, M. R., Parker, B. A., Raholijao, N., \& Nassor, A. (1995). Variability of summer rainfall over Madagascar: climatic determinants at interannual scales. Int. J. Climatol., 15, 1323-1332. 
Kalnay, E. et al. (1996). The NCEP/NCAR 40-Year Reanalysis Project. Bull. Amer. Meteor. Soc., 77, 437-471.

Kistler, R. et al. (2001). The NCEP-NCAR 50-Year Reanalysis. Bull. Amer. Meteor. Soc., 82, 247-268.

Knapp, K. R., Kruk, M. C., Levinson, D. H., Diamond, H. J., \& Neumann, C. J. (2010). The International Best Track Archive for Climate Stewardship (IBTrACS): Unifying Tropical Cyclone Data. Bull. Amer. Meteor. Soc., 91, 363-376.

Lin, Y.-L. (1993). Orographic effects on airflow and mesoscale weather systems over Taiwan. Terr. Ocean. Atmos., 4, 381-420.

Lin, Y.-L. (2007). Mesoscale Dynamics. Cambridge University Press, pp. 630.

Lin, Y.-L., \& Savage III, L. C. (2011). Effects of landfall location and the approach angle of a cyclone vortex encountering a mesoscale mountain range. J. Atmos. Sci., 68, 2095-2106.

Lin, Y.-L., Chen, S.-Y., Hill, C. M., \& Huang, C.-Y. (2005). Control parameters for the influence of a mesoscale mountain range on cyclone track continuity and deflection. J. Atmos. Sci., 62, 1849-1866.

Lin, Y.-L., Chiao, S., Wang, T.-A., Kaplan, M. L., \& Weglarz, R. P. (2001). Some common ingredients for heavy orographic rainfall. Wea. Forecasting, 16, 633-660.

Lorenz, E. N. (1956). Empirical Orthogonal Functions and Statistical Weather Predic- tion. Technical Report, Statistical Forecast Project Report 1. Dept. of Meteor. MIT, pp. 49.

Mark R. J., Pathack, B., Wang, B., Powell, M., \& Raholijao, N. (1993). A Destructive Tropical Cyclone Season in the SW Indian Ocean: January-February 1984. South African Geograph. J., 75, 53-59.

Nuzzo, R. (2014). Scientific method: Statistical errors. Nature, 506, 150-152.

Pearson, K. (1992). On lines and planes of closest fit to systems of points in space. Phil. Mag., 2, 559-572.

Ramsay, H. A., Camargo, S. J., \& Kim, D. (2012) Cluster analysis of tropical cyclone tracks in the Southern Hemisphere.Clim. Dyn., 39, 897-917.

Rocha, A., \& Simmonds, I. H. (1997a). Interannual variability of south-eastern African summer rainfall. Part 1: Relationships with air-sea interaction processes. Int'l J. Climatol., 17, 235-265.

Rocha, A., \& Simmonds, I. H. (1997b). Internannual variability of Southern African summer rainfall. Part II: Modelling the impact of sea surface temperatures on rainfall and circulation. Int. J. Clim., 17, 267-290

Rostom, R., \& Lin, Y.-L. (2015). Control parameters for track continuity of cyclones passing over the southern-central Appalachian Mountains. Wea. Forecasting, 30, 1429-1449.

Rostom, R., \& Lin, Y.-L. (2016). Common ingredients and orographic rain index for heavy precipitation associated with Hurricanes Hugo (1998) and Isabel (2003) over the Appalachian Mountains. Quart. J. Roy. Meteor. Soc., in review.

Smith, R. B. (1979). The influence of mountains on the atmosphere. Adv. Geophys., 21, 87-230, Academic Press.

Smolarkiewicz, P. K., \& Rotunno, R. (1989). Low Froude number flow past three-dimensional obstacles. Part I: Baroclinically generated lee vortices. J. Atmos. Sci., 46, 1154-64.

Wikipedia. (2016). Tropical Storm Domoina. https://en.wikipedia.org/wiki/Tropical_Storm_Domoina.

Wilks, D. S. (1995). Statistical methods in the atmospheric sciences(2nd ed.). Int'l Geophys. Ser., 59, 464, Academic Press.

Witcraft, N. C., Lin, Y.-L., \& Kuo, Y.-H. (2005). Dynamics of Orographic Rain Associated with the Passage of a Tropical Cyclone over a Mesoscale Mountain. Terres. Atmos. Ocean. Sci.,16, 1133-1161.

\section{Copyrights}

Copyright for this article is retained by the author(s), with first publication rights granted to the journal.

This is an open-access article distributed under the terms and conditions of the Creative Commons Attribution license (http://creativecommons.org/licenses/by/4.0/). 